\title{
The everolimus-eluting Xience stent in small vessel disease: bench, clinical, and pathology view
}

This article was published in the following Dove Press journal:

Medical Devices: Evidence and Research

30 December 2014

Number of times this article has been viewed

\section{Oscar D Sanchez \\ Kazuyuki Yahagi \\ Tobias Koppara \\ Renu Virmani \\ Michael Joner \\ CVPath Institute, Inc., Gaithersburg, MD, USA}

Correspondence: Michael Joner

CVPath Institute, Inc., 19 Firstfield Road,

Gaithersburg, MD 20878, USA

$\mathrm{Tel}+$ I 30 I 2083570

Fax +I 30I 2083745

Email mjoner@cvpath.org
Abstract: Coronary artery disease (CAD) is the leading cause of morbidity and mortality worldwide. The pathogenesis of CAD relates to the presence of atherosclerotic plaques in the coronary arteries, which are most frequently treated today by percutaneous coronary intervention. Small vessel disease treatment represents one-third of all percutaneous coronary interventions with higher rates of restenosis and major adverse cardiac events. Initially, drug-eluting stents (DES) were developed to reduce in-stent restenosis, improving clinical outcomes and reducing the need for target vessel revascularization. However, late and very late stent thrombosis emerged as a new problem compromising DES's long-term results. The cobalt-chromium everolimus-eluting stent (CoCr-EES) represents the results of an evolutionary process in DES technology aimed at improving the shortcomings of first-generation DES. Small vessel CAD has historically been an obstacle to long-term patency following implantation of DES. Antirestenotic efficacy has been shown to be of high relevance in small vessels. Therefore, stent selection may play an important role in determining outcomes in this subgroup of patients. This article will review the performance of CoCr-EES in the treatment of small vessel CAD from preclinical, clinical, and pathology perspectives, and it will highlight the most important findings in this regard.

Keywords: small vessel, cobalt-chromiun everolimus-eluting stent, Xience V, pathology

\section{Introduction}

Percutaneous coronary intervention (PCI) has become the first-line treatment for patients suffering from obstructive coronary artery disease (CAD). Drug-eluting stents (DES) have significantly reduced the risk of restenosis and the need for repeat revascularization when compared to bare metal stent (BMS). ${ }^{1}$ In the RAVEL and SIRIUS trials, ${ }^{2,3}$ when compared to BMS, DES improved restenosis rates and late lumen loss, and decreased target lesion revascularization (TLR) from $16.6 \%$ to $4.1 \%$ $(P<0.01)$. Although first-generation DES (1st Gen DES) were introduced to disrupt neointimal growth by the use of antiproliferative drugs, this benefit was acquired at the expense of a substantial delay in vascular healing and the clinical consequences of late and very late stent thrombosis (LST/VLST). ${ }^{4}$ Second-generation DES (2nd Gen DES) were developed with newer alloys, biocompatible polymers, thinner struts, and different drugs kinetics, resulting in a reduction of LST/VLST. Small vessel CAD accounts for up to $30 \%$ of all $\mathrm{PCI}^{5}$ and remains an independent predictor of angiographic restenosis and TLR, even after the introduction of DES. ${ }^{6}$ The cobalt-chromium everolimus-eluting stent (CoCr-EES) (Xience ${ }^{\circledR}$ V; Abbott Vascular, Santa Clara, California, USA) has been reported as one of the most frequently used 2nd Gen DES with better event-free survival rates in small vessels. ${ }^{7}$ This review article discusses 
the preclinical, clinical, and pathological performance of CoCr-EES in small vessel CAD.

\section{Device characteristics Xience V}

The antiproliferative drug used is everolimus, a hydroxyethyl derivative of sirolimus which acts as an immunosuppressant. It induces cell cycle arrest in the $\mathrm{G}_{1}$ phase by inhibiting the mammalian target of rapamycin, a serine/threonine protein kinase that regulates cell growth, proliferation, motility, protein synthesis, and transcription, among others. ${ }^{8,9}$ The polymer is a thin $(7.8 \mu \mathrm{m})$ bio-inert, non-erodible, and ultra-pure fluorinated copolymer (poly-n-butyl methacrylate [PBMA] and poly-vinylidene fluoride and hexafluoropropylene [PVDF-HFP]) that provides both elasticity and stability. PBMA serves as a base coat for the stent and facilitates anchorage of PVDF-HFP, which serves as a matrix layer containing the drug at a ratio of $83 \% / 17 \%$ for polymer/ everolimus, respectively, and no top-coat layer is applied. The polymer composition provides mechanical integrity after stent deployment, followed by the controlled release of everolimus at a total dose of $100 \mu \mathrm{g} / \mathrm{cm}^{2}$, delivering up to $80 \%$ of the drug after 4 weeks. ${ }^{10}$ The platform is the Multilink ${ }^{\mathrm{TM}}$ Vision L-605 cobalt chromium alloy with a strut thickness of $81 \mu \mathrm{m}$ mounted on a compliant tapered Vision balloon, ${ }^{11}$ structurally designed to improve deliverability and conformability, and at the same time, increasing its radiopacity, radial strength, and fracture resistance. ${ }^{12}$

The Xience $V$ and Xience nano share the same platform design, delivery system, drug, and coating materials. The differentiating features of the Xience nano pertain to a balloon diameter of $2.25 \mathrm{~mm}$ with a nominal inner stent diameter of $2.25 \mathrm{~mm}$, as compared to Xience V, which is available at diameters of $2.5 \mathrm{~mm}, 2.75 \mathrm{~mm}, 3.0 \mathrm{~mm}, 3.5 \mathrm{~mm}$, and $4.0 \mathrm{~mm}$.

\section{Preclinical findings}

There are several stent-related factors that have been associated with LST/VLST, such as strut thickness, polymer characteristics, coating integrity, and drug dose, among others. ${ }^{13,14}$ It is known that strut thickness affects the angiographic and clinical outcome after PCI. ${ }^{15}$ In this regard, DES with thinner struts have been reported to provide improvement in outcomes with respect to target vessel revascularization when compared to thicker strut DES in calcified lesions. ${ }^{16}$ Kolandaivelu et a ${ }^{17}$ evaluated the impact of strut thickness on thrombogenicity in a Chandler loop model. Two main factors were reported to determine acute thrombogenicity: 1) strut thickness; and
2) polymer coating. Thrombogenicity within the various BMS designs correlated with strut thickness; stents with thicker struts were $49 \%$ more thrombogenic than stents with thinner struts $(0.88 \pm 0.38$ for struts $<100 \mu \mathrm{m}$ versus $1.44 \pm 0.65$ for struts $>100 \mu \mathrm{m} ; P=0.036$ ). After 3 days of implantation in porcine coronary arteries, stents with thicker struts demonstrated significantly more thrombus and $62 \%$ more clots compared to their thinner strut counterparts $\left(0.21 \pm 0.041 \mathrm{~mm}^{2}\right.$ versus $\left.0.13 \pm 0.019 \mathrm{~mm}^{2} ; P=0.004\right)$; also, neointimal fibrin accumulated to a greater extent around the thicker struts compared to the thinner struts $(1.56 \pm 0.40$ versus $0.83 \pm 0.41$; $P=0.016$ ). The authors also evaluated overlapping stents, which were more thrombogenic than single length-matched controls, more so for thicker than thinner struts stents (2.32 \pm 0.96 and $3.25 \pm 0.11$ versus $1.00 \pm 0.17 ; P<0.001)$. Moreover, overlapping thinner strut DES $(0.51 \pm 0.019)$ were less thrombogenic than overlapping BMS $(P<0.001)$ and even the single BMS controls $(P<0.001) .{ }^{17}$ In this landmark study, Kolandaivelu et $\mathrm{al}^{17}$ also found that coated stents were less thrombogenic than corresponding BMS $(0.76 \pm 0.02$ versus $1.00 \pm 0.15 ; P<0.002)$, and clot mass was also significantly lower for DES when compared with BMS $(0.67 \pm 0.35$ versus $1.03 \pm 0.54 ; P=0.011$ ).

Hypersensitivity reactions induced by the durable polymers used in 1st Gen DES were suggested to contribute to the occurrence of LST. ${ }^{18-20}$ Recent advances in stent technology, with the introduction of more biocompatible polymers, have reduced the risk of this complication..$^{21,22}$ Chin-Quee et $\mathrm{al}^{23}$ evaluated two different polymers currently available for DES in rabbit iliac arteries where $\mathrm{CoCr}$ stents were coated with PVDF-HFP or phosphorylcholine polymer (without drug) and assessed for endothelialization at 14 days by confocal and scanning electron microscopy (SEM). Endothelialization was equivalent and near complete for PVDF-HFP versus phosphorylcholine polymer-coated stents ( $>80 \%$ by SEM). Also, acute thrombogenicity was assessed in a Chandler loop model using porcine blood; thrombus adherence was similar for both polymers $(0.94 \pm 0.23$ versus $0.99 \pm 0.20)$. These results suggest that the polymers examined here did not impede endothelization. ${ }^{23}$

Polymer coating defects can potentially change the drug elution kinetics of DES, or they can lead to chronic inflammatory reactions. ${ }^{17}$ Furthermore, the nonuniform coating of stent struts may impact platelet adhesion and endothelialization. Finally, coating fragments may embolize downstream, resulting in myocardial ischemia. Yazdani et al ${ }^{24}$ evaluated 48 DES for coating integrity in CoCr-EES, zotarolimuseluting stent (ZES), paclitaxel-eluting stent (PES), and 
biolimus A-9-eluting stent (BES) in a rabbit iliofemoral stent model for durations of 7 days, 28 days, 90 days, and 180 days. The CoCr-EES and ZES had the least amount of coating defects as compared to the PES and BES. However, coating defects were shown to increase over time within the ZES, whereas in the CoCr-EES, the amount of irregularity remained constant over time.

Early re-endothelialization after stent implantation is the key to decreasing thrombogenicity. Newer generation DES were designed to outperform first-generation devices in this regard. In our laboratory, ${ }^{25}$ we compared 1 st Gen DES and 2nd Gen DES in New Zealand White Rabbits and reported at 14 days that re-endothelialization above struts was variable among stents with significantly greater coverage in CoCr-EES $(64.0 \% \pm 27.5 \%)$, followed by ZES $(30.2 \% \pm 14.2 \%), \operatorname{PES}(26.8 \% \pm 15.8 \%)$, and sirolimus-eluting stent (SES) $(6.4 \% \pm 4.2 \%)$, with a statistically significant difference versus CoCr-EES $(P<0.003)$ and BMS $(P<0.0001)$ as a control stent (Figure 1). At 28 days, all evaluated stents had more than $60 \%$ endothelial cell coverage above struts in favor of CoCr-EES, but without statistically significant differences among groups. Furthermore, CoCr-EES had the least percentage of struts lacking endothelial coverage compared to other DES. ${ }^{25}$ Based on morphometry, the greatest frequency of uncovered struts was observed in the middle stented segment, while proximal and distal segments showed overall greater coverage. We also evaluated endothelium integrity using the platelet-endothelial cell adhesion molecule, PECAM-1, as a surrogate, and found that CoCr-EES had significantly greater cell-to-cell contact sites above the struts, which demonstrates a functionally and biologically active endothelium. ${ }^{25}$

\section{Clinical findings}

Randomized controlled clinical trials have established differential outcomes in the safety and efficacy of DES used in distinct clinical settings, and stent-related factors may play an important role in the scenery of small vessel PCI. ${ }^{13,14,26}$ Cannon et $\mathrm{al}^{27}$ evaluated the safety of Xience Nano ${ }^{\mathrm{TM}}$ in vessels $>2.25 \mathrm{~mm}$ but $<2.5 \mathrm{~mm}$ at 1 -year follow-up. The authors established a performance goal (PG) at $20.4 \%$

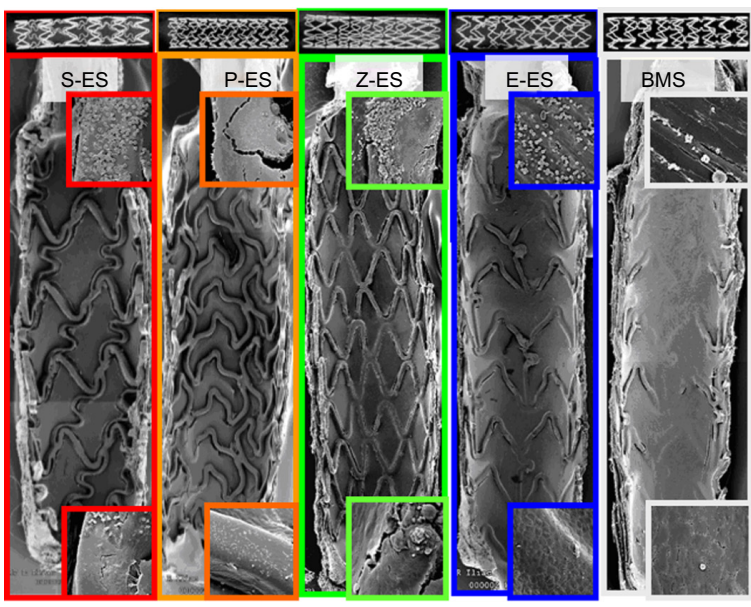

En face SEM analysis of 14-day comparator stents

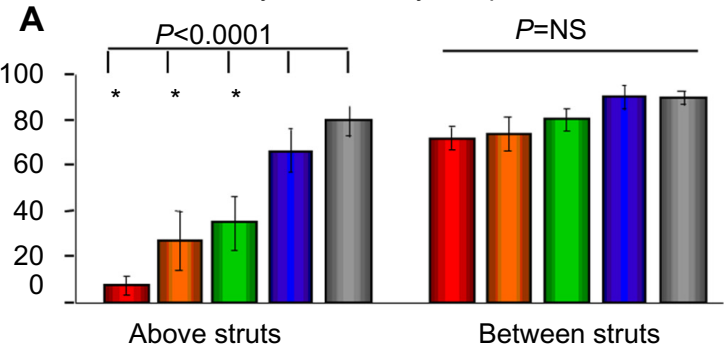

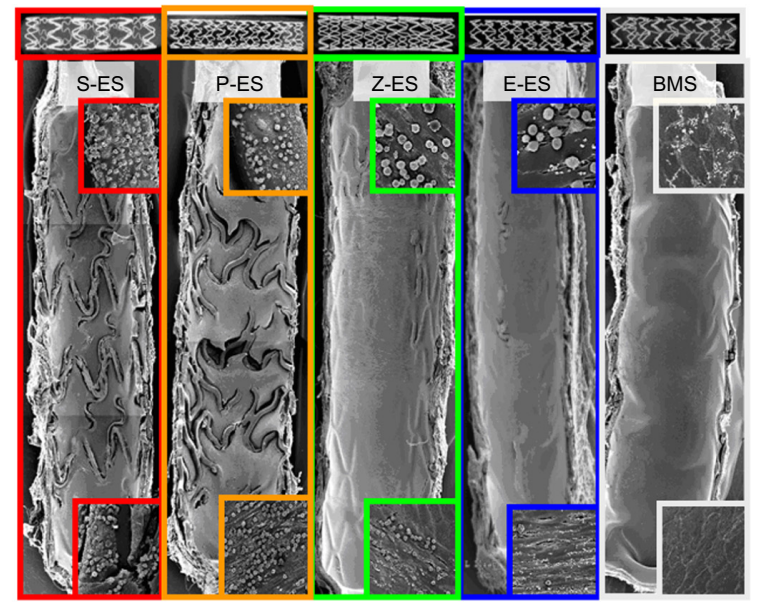

En face SEM analysis of 28-day comparator stents

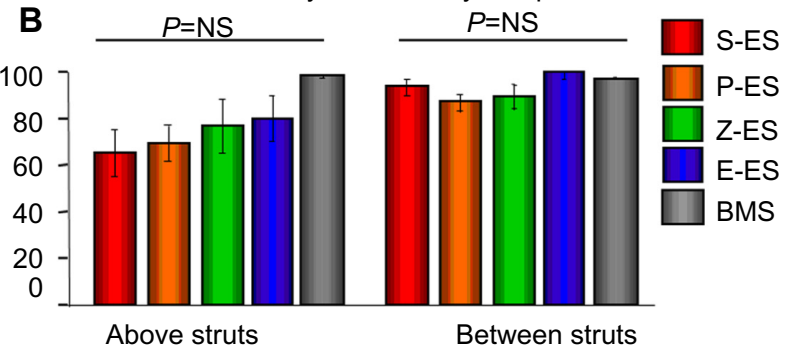

Figure I SEM and quantitative analysis of endothelial coverage based on morphometric analysis of I4- and 28-day comparator DES and BMS controls.

Notes: The upper panels show corresponding radiographic images of each stent. The lumens are clearly patent and the struts are easily discerned underneath a thin neointimal surface. Among DES, there is less endothelial cell surface coverage in SES and PES when compared with ZES and EES. The panel insets are representative images at higher magnification $(\times 200)$ from proximal and distal regions showing bare struts, surface thrombi, inflammatory cells, and endothelial cells. Bar graphs showing the quantitative analysis of endothelial coverage above and between struts at (A) 14 days and (B) 28 days. Comparator DES and BMS based on morphometric analysis of images from SEM. Reprinted from J Am Coll Cardiol, 52(5), Joner M, Nakazawa G, Finn AV, et al, Endothelial cell recovery between comparator polymer-based drug-eluting stents, (C) Copyright 2008, with permission from Elsevier. ${ }^{25}$

Abbreviations: SES, sirolimus-eluting stents; PES, paclitaxel-eluting stents; ZES, zotarolimus-eluting stents; EES, everolimus-eluting stents; BMS, bare metal Multilink Vision control stents; SEM, scanning electron microscopy; NS, not significant; DES, drug-eluting stents. 
for target lesion failure (TLF) based on clinical trials and registries, which evaluated $2.25 \mathrm{~mm}$ diameter DES. ${ }^{14,28,29}$ The 1-year TLF rate was $8.1 \%$, with an upper one-sided limit ( $95 \%$ confidence interval) of $13.0 \%$, meeting the PG of $20.4 \%$ $(P<0.0001)$. The 1 -year TLF rate was mainly driven by low cardiac death and myocardial infarction (MI) rates. The most important difference noted in this study was a higher TLF rate for the reference vessel diameter (RVD) $\leq 2.12 \mathrm{~mm}$ (number [n] $=72$ ), which reached $13.89 \%$, compared to $1.56 \%$ for a RVD $>2.12 \mathrm{~mm}(\mathrm{n}=64)$. In a post hoc analysis, a subgroup of diabetics was also evaluated by the authors. Clinically, no statistically significant differences were found for TLF $(5.7 \%$ versus $4.9 \% ; P=1.0)$ and major adverse cardiovascular event rates (MACE)/TLF rates $(7.5 \%$ versus $8.5 \% ; P=1.0)$ in diabetics versus nondiabetics, respectively. Also, angiographically, in-stent and in-segment late loss showed no difference between diabetics and nondiabetics $(0.22 \pm 0.47 \mathrm{~mm}$ versus $0.19 \pm 0.36 \mathrm{~mm}, P=0.83$; and $0.14 \pm 0.48 \mathrm{~mm}$ versus $0.17 \pm 0.38 \mathrm{~mm}$, respectively, $P=0.76) .{ }^{27}$

Small vessel CAD represents a challenge for interventional cardiologists, with higher restenosis and stent thrombosis (ST) rates. ${ }^{30,31}$ Hermiller et al ${ }^{32}$ evaluated the safety of CoCr-EES in small and nonsmall vessels in a real-world scenario, applying a $2.5 \mathrm{~mm}$ diameter cut-off. The mean RVD for small vessels was $2.55 \pm 0.36 \mathrm{~mm}$ and $3.25 \pm 0.46 \mathrm{~mm}$ for the nonsmall vessel group $(P<0.001)$. Definite or probable $\mathrm{ST}$ rates were low and not significantly different between the groups at $0.37 \%$ versus $0.40 \%(P=0.88)$ for the small and nonsmall vessel groups, respectively. The composite rate of cardiac death or MI was comparable for the small and nonsmall vessel group ( $4.5 \%$ versus $5.1 \%$, respectively; $P=0.57$ ). The 1-year TLR rate was also comparable in the small vessel group (small group 3.8\% versus nonsmall group 3.0\%; $P=0.35$ ). This study demonstrated the safety of CoCr-EES in small vessels despite the fact that this group consisted of more females, those with a higher rate of diabetes, and those with more complex lesion characteristics. ${ }^{32}$

In a separate study, Ito et $\mathrm{al}^{33}$ compared CoCr-EES and PES for small vessel revascularization by pooling the data from the SPIRIT III and IV trials. ${ }^{34,35}$ From 4,689 patients, two groups were analyzed: the small vessel group (RVD: $2.25 \pm 0.19 \mathrm{~mm}$; $\mathrm{n}=1,019$ ) and the large vessel group (RVD: $2.99 \pm 0.35 \mathrm{~mm}$; $\mathrm{n}=2,586$ ). After 1-year follow-up, in patients with small vessels disease, the TLF (CoCr-EES 4.4\% versus PES 7.9\%; $P=0.03$ ) and MACE (CoCr-EES 4.5\% versus PES 7.9\%; $P=0.04$ ) were significantly reduced in favor of CoCr-EES. The clinical endpoint, TLF, was composed of cardiac death, target vessel MI, and ischemia driven-TLR (ID-TLR). Amid the others, only
ID-TLR showed a significant reduction at 1 year (everolimuseluting stents [EES] $2.4 \%$ versus PES 5.5\%; $P=0.02$ ). Although, ST showed higher rates in small vessel revascularization, the authors found that ST was significantly lower in patients with small vessels treated with CoCr-EES than in those treated with PES $(0.2 \%$ versus $1.2 \%$, respectively; $P=0.04){ }^{33}$

Currently, the factors predictive of in-stent restenosis can be divided into patient-related, procedure-related, and lesionrelated factors. Patient-related factors such as diabetes, a history of restenosis, and genetic factors have been reported as risk factors of in-stent restenosis. ${ }^{33}$ Procedure-related factors include the number of stents implanted, the total stent length, and stent overlap. Lesion-related characteristics, which impact the rate of restenosis, include small vessel size, long lesion length, and the severity of pretreatment as well as posttreatment lesion stenosis, among others. ${ }^{36}$ Claessen et $\mathrm{al}^{37}$ collected data from SPIRIT II, III, and IV,,$^{34,38,39}$ and combined three groups: short lesions in large vessels (group A); long lesions in large vessels or short lesions in small vessels (group B); and long lesions in small vessels (group C) to evaluate the safety and efficacy of CoCr-EES versus PES. The MACE rate after 2 years of follow-up was lower in group A, intermediate in group B, and highest in group $\mathrm{C}(5.6 \%$ versus $8.2 \%$ versus $10.4 \%$, respectively; $P<0.0001)$. Also, a similar trend was observed for MI (3.3\% versus $3.0 \%$ versus $4.5 \%$, respectively; $P=0.02$ ) and ID-TLR (2.9\% versus $5.0 \%$ versus $6.3 \%$, respectively; $P=0.0002)$. The authors also evaluated MACE rates by stent type (PES and CoCr-EES), and found that the higher the lesion complexity, the greater the MACE incidence $(7.0 \%$, $11.2 \%$, and $12.8 \%$ for PES, respectively, $P=0.007$; versus $4.8 \%$ versus $6.6 \%$ versus $9.1 \%$ for CoCr-EES, respectively, $P=0.001)$. On the other hand, the 2-year rate of definite or probable ST (Academic Research Consortium, ARC definition) also increased with greater lesion complexity after PES implantation (group A $0.7 \%$ versus group B 1.9\% versus group $\mathrm{C} 2.8 \% ; P=0.03$ ), but that relationship was not present after CoCr-EES implantation $(0.9 \%$ versus $0.6 \%$ versus $0.6 \% ; P=0.65)$. CoCr-EES were associated with significantly lower rates of MACE, MI, ID-TLR, and ST in groups B and $\mathrm{C}$, but no statistical significance was found in the less complex group (group A). Multivariate analysis found that the use of CoCr-EES rather than PES was an independent predictor of freedom from MACE in group $\mathrm{B}(P<0.0001)$ and group $\mathrm{C}$ $(P=0.004)$, but not in group $\mathrm{A}(P=0.19) .{ }^{37}$

\section{Pathology findings}

Recently, we reported ${ }^{40}$ the pathologic findings of 2 nd Gen DES and compared these to 1 st Gen DES. A total 
of 204 lesions ( $\mathrm{SES}=73$; PES =85; CoCr-EES =46) from 149 autopsy cases with implant duration $>30$ days and $\leq 3$ years were pathologically analyzed to determine differences. The observed frequency of LST and VLST was less for CoCr-EES (4\%) compared with SES (21\%; $P=0.029)$ and PES $(26 \% ; P=0.008)$. The prevalence of restenosis for CoCr-EES (17\%) did not differ significantly from that observed in SES (14\%) and PES (12\%). The frequency of uncovered struts was markedly lower for CoCr-EES (2.6\%) as compared to SES $(18.0 \% ; P<0.0005)$ and PES $(18.7 \%$; $P<0.0005)$. The prevalence of DES with $>30 \%$ uncovered struts was also significantly lower in CoCr-EES (20\%) than in SES $(60 \% ; P<0.0005)$ and PES $(67 \% ; P<0.0005)$. In terms of inflammation, CoCr-EES showed significantly lower inflammatory scores compared with SES. The overall prevalence of neoatherosclerosis after CoCr-EES implantation in native coronary arteries was $29 \%$, which did not differ significantly from SES $(35 \% ; P=0.62)$ and PES $(19 \%$; $P=0.47) .^{40}$

Complex lesion characteristics and unstable plaques are associated with a greater delay in arterial healing when compared to PCI of a simple and stable plaque by pathology. ${ }^{41}$ Therefore, we evaluated the prevalence of $>30 \%$ uncovered struts in the setting of off-label versus on-label clinical indications. CoCr-EES compared with SES and PES showed greater strut coverage for both on-label (14\% versus $50 \%$ versus $57 \%$, respectively) and off-label (25\% versus $68 \%$ versus $75 \%$, respectively) indications.

When analyzing the CVPath stent database composed of 865 cases, 68 had CoCr-EES implanted and 12 cases were found with a stent diameter of $2.5 \mathrm{~mm}$ or less (Table 1). From those 12 cases, five had a duration of $<30$ days $(6.8 \pm 5.1$ days). The mean stent length was $35.6 \pm 24.9 \mathrm{~mm}$ and the mean stent diameter was $2.3 \pm 0.27 \mathrm{~mm}$. Stent-related death occurred in two cases. Case 1: a 45-year-old woman with obesity, hypertension, and diabetes who presented with MI secondary to involvement of the left circumflex artery, which was revascularized; 5 days after the procedure, she died suddenly with ST. Case 2: a 58-year-old male with a history of obesity and CAD presented with non-ST segment elevation MI, and left anterior descending artery occlusion in the region of the left diagonal branch; bifurcation stenting was performed. The patient died suddenly 7 days after the procedure; at autopsy, there was a large infarction and mild to moderate thrombus in the stented region. The other three patients had stable CAD and only mild inflammation was observed with moderate peristrut fibrin and platelet deposition (Figure 2).
Table I CVPath Institute database for CoCr-EES $\leq 2.5 \mathrm{~mm}$ stents

\begin{tabular}{|c|c|c|c|}
\hline Parameter & Globally & $<\mathbf{3 0}$ days & $>30$ days \\
\hline \multicolumn{4}{|c|}{ CVPath database - CoCr-EES $<2.5 \mathrm{~mm}$} \\
\hline Number of patients & 12 & 5 & 7 \\
\hline $\begin{array}{l}\text { Age, years - } \\
\text { mean (SD) }\end{array}$ & $57.6( \pm 10.5)$ & $57.8( \pm \mid 4.2)$ & $57.6( \pm 8.3)$ \\
\hline Male & $75 \%$ & $80 \%$ & $71.4 \%$ \\
\hline HTN & $41.7 \%$ & $60 \%$ & $28.5 \%$ \\
\hline DM & $75 \%$ & $80 \%$ & $71.5 \%$ \\
\hline HPL & $16.7 \%$ & $20 \%$ & $14.3 \%$ \\
\hline Prior MI & $58.3 \%$ & $40 \%$ & $71.2 \%$ \\
\hline \multicolumn{4}{|l|}{ Vessel treated } \\
\hline LAD & $41.7 \%$ & $40 \%$ & $42.9 \%$ \\
\hline LCx & $50 \%$ & $40 \%$ & $57.1 \%$ \\
\hline RCA & $8.3 \%$ & $20 \%$ & $0 \%$ \\
\hline $\begin{array}{l}\text { Stent/lesion } \\
\text { mean (SD) }\end{array}$ & $1.75( \pm 0.97)$ & $2( \pm I)$ & $1.57( \pm 0.98)$ \\
\hline $\begin{array}{l}\text { Stent length } \\
\text { mean (SD) }\end{array}$ & $29.08( \pm 17.6)$ & $35.6( \pm 24.9)$ & $24.43( \pm 9.6)$ \\
\hline $\begin{array}{l}\text { Stent diameter } \\
\text { mean }(S D)\end{array}$ & $2.29( \pm 0.25)$ & $2.3( \pm 0.27)$ & $2.28( \pm 0.27)$ \\
\hline $\begin{array}{l}\text { Duration } \\
\text { mean (SD) }\end{array}$ & $144.5( \pm 204.5)$ & $6.8( \pm 5.1)$ & $242.9( \pm 222.6)$ \\
\hline Indication - AMI & $30 \%$ & $40.0 \%$ & $14.3 \%$ \\
\hline \multicolumn{4}{|l|}{ Cause of death } \\
\hline SR & $25 \%$ & $40.0 \%$ & $14.3 \%$ \\
\hline NSR & $50 \%$ & $60.0 \%$ & $42.9 \%$ \\
\hline NC & $25 \%$ & $0 \%$ & $42.9 \%$ \\
\hline Restenosis & $8.3 \%$ & $0 \%$ & $14.3 \%$ \\
\hline Thrombosis & $16.7 \%$ & $20.0 \%$ & $14.3 \%$ \\
\hline Malappose & $0 \%$ & $0 \%$ & $0 \%$ \\
\hline Fracture & $16.7 \%$ & $20 \%$ & $0 \%$ \\
\hline
\end{tabular}

Note: Clinical, angiography, and pathological findings from 12 autopsy cases. Abbreviations: CoCr-EES, cobalt-chromium everolimus-eluting stent; SD, standard deviation; HTN, hypertension; DM, diabetes mellitus; HPL, hyperlipidemia; MI, myocardial infarction; LAD, left anterior descending artery; LCx, left circumflex; RCA, right coronary artery; AMI, acute myocardial infarction; SR, stent-related; NSR, nonstent-related; NC, noncardiac.

One of the three cases had thrombosis and stent fracture $(20 \%)$; the other two were nonstent-related deaths.

The remaining seven cases (Table 1) had a duration $>30$ days ( $242.9 \pm 222.6$ days). The mean length was $24.4 \pm 0.27 \mathrm{~mm}$ and the mean diameter was $2.28 \pm 0.27 \mathrm{~mm}$. Acute coronary syndrome was the indication in one case (14.3\%), and the cause of death was stent-related - a 72-yearold woman with obesity, hypertension, diabetes, atrial fibrillation, and a history of multiple revascularizations. She died from ST 210 days later with underlying restenosis. For the rest of the cases $(n=6)$ with duration $>30$ days, there were no differences in the principal histopathological findings among those presenting with acute coronary syndrome versus stable CAD. Overall, the histopathological analysis showed mild to moderate chronic peristrut inflammation consisting of monocytes, T-lymphocytes, and macrophages (Figure 3) without any significant eosinophils. Also, mild neointimal 


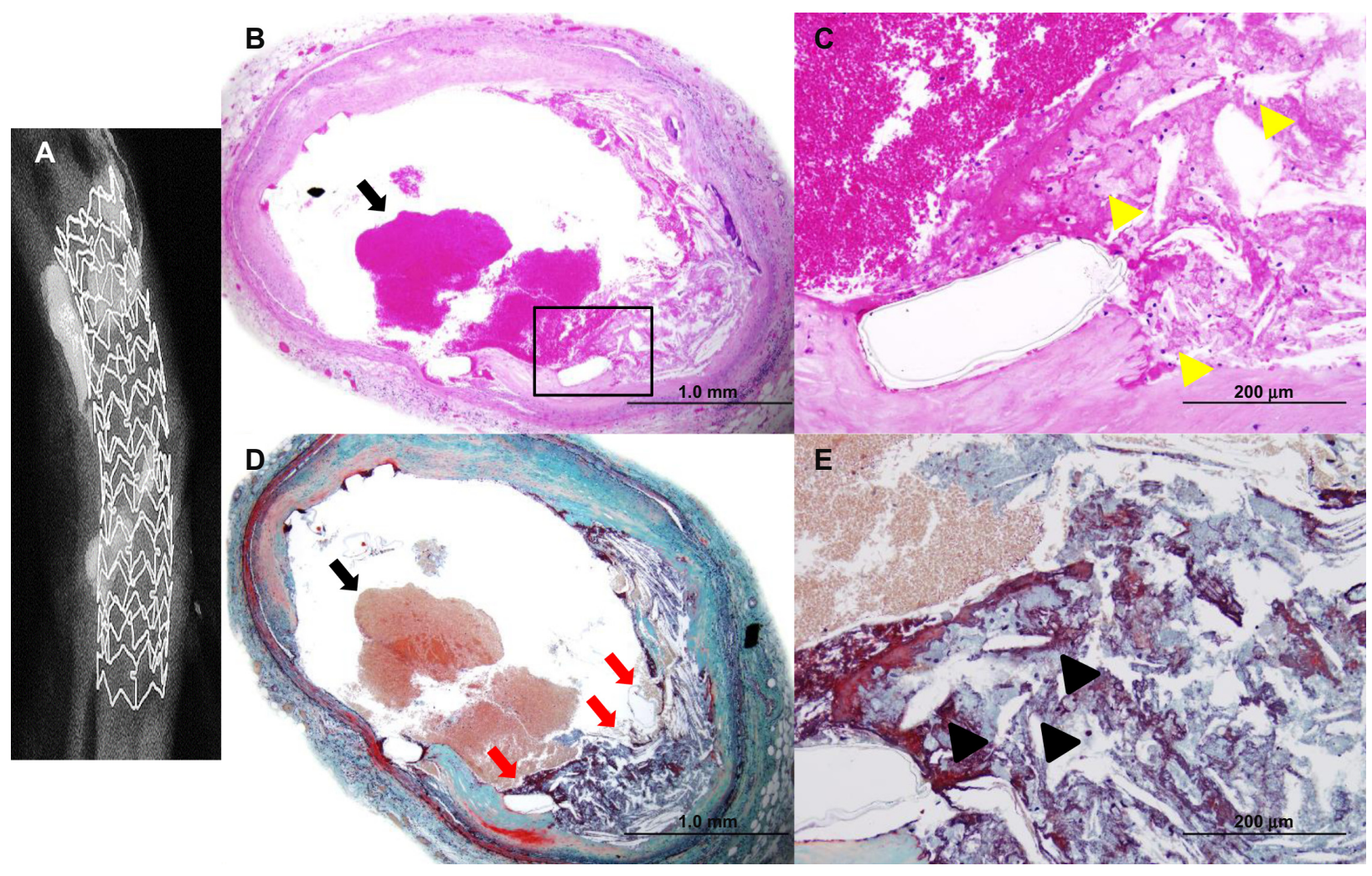

Figure 2 78-year-old male with history of HTN, DM and hyperlipidemia, complained of chest pain, underwent placement of two stents and suddenly died 7 days later. A $2.0 \times 12 \mathrm{~mm}$ Xience $V$ stent was placed in the distal RCA (A). Histopathology showed post-mortem thrombus (black arrows, panels B and D), also mild acute inflammatory cells (yellow arrowheads, panel $\mathbf{C}$ ) in the surrounding of stent struts is seen. Necrotic core penetration and prolapse (red arrows, panel $\mathbf{D}$ ) and cholesterol clefts are shown (black arrowhead, panel E). (H\&E and Movat $2 \times$ and $4 \times$ and $20 \times$ )

Abbreviations: HTN, hypertension; DM, diabetes mellitus; RCA, right coronary artery.
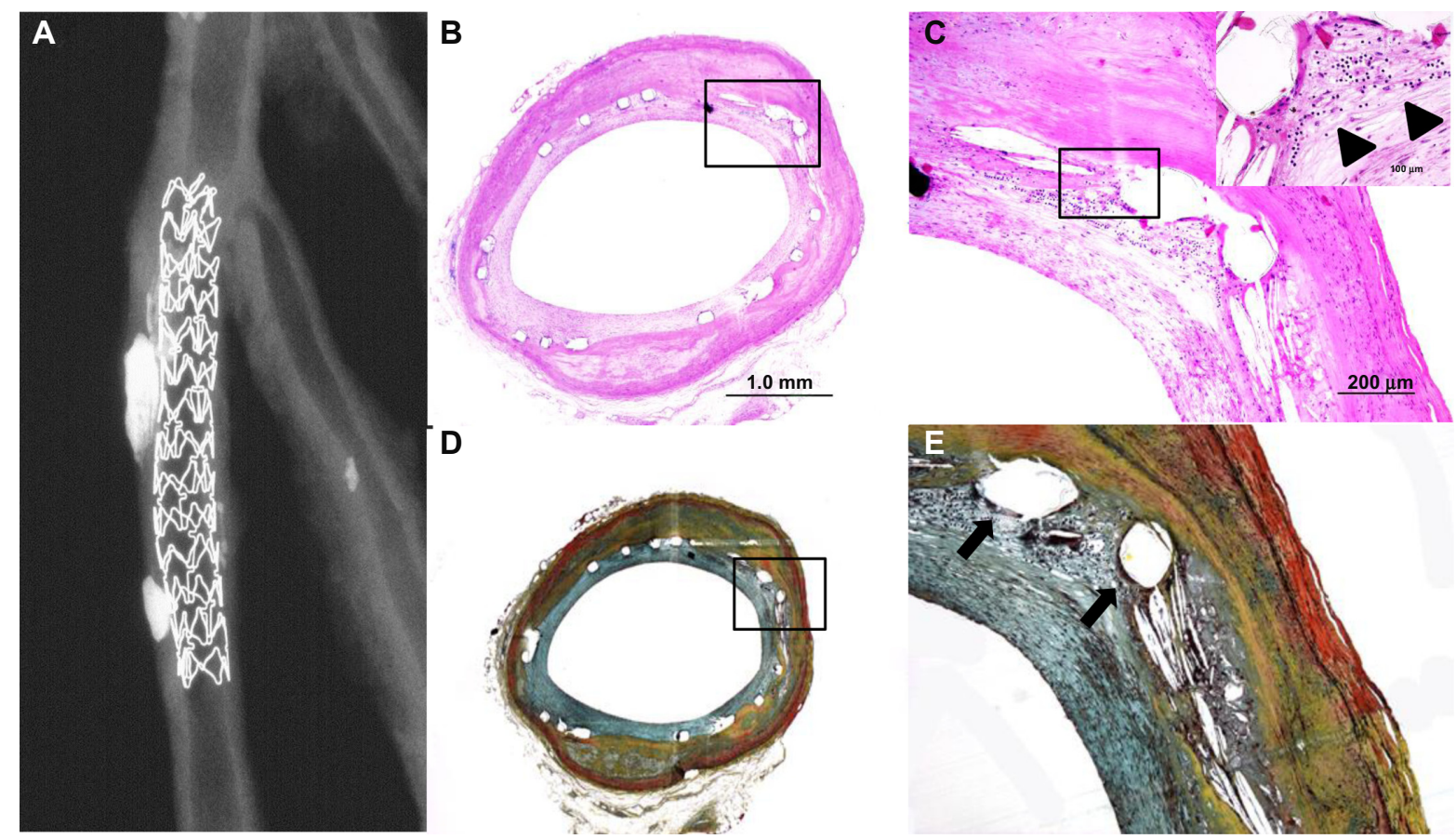

D

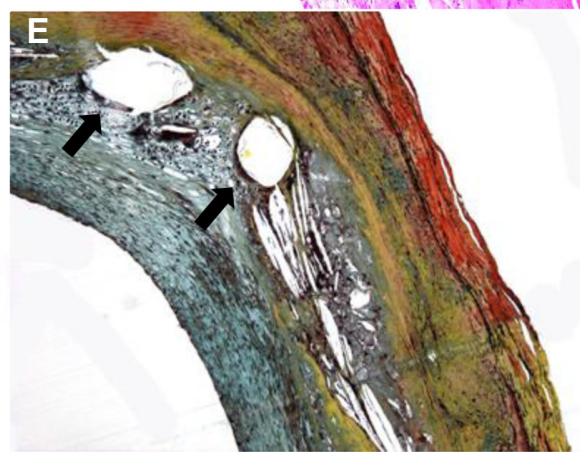

Figure 3 60-year-old male with history of DM and MI with stent placement in 2009, presented with sudden death. A 2.0×18 mm Xience $\mathrm{V}$ stent was placed in the mid LAD (A). Histopathology showed mild neointimal proliferation (B), mild chronic inflammation (black arrowheads, panel C) and focal peri-strut fibrin (panel C); some struts positioned in necrotic core (black arrows, panel D and E) (H\&E and Movat $2 \times$ and $4 \times$ and 20x). 
growth was seen in the majority of cases. Restenosis was observed in one of the six cases; however, the Xience case was sandwiched between two Vision stents, both of which had total occlusion.

Nevertheless, we must recognize the limited number of cases analyzed at autopsy. A greater number of cases and matched control groups will be required to understand the full scope of histopathological findings of CoCr-EES in small vessel disease.

\section{Summary}

DES have progressively improved clinical outcomes, but the potential risk of ST is still a concern and limits the use of DES, especially in small vessel CAD. Overall, LST and VLST have been reported with an incidence of $0.2 \%$ and $0.4 \%$ per year, respectively. ${ }^{42}$ However, considering the large amount of stents implanted worldwide, those numbers are still high. Several reports of ST have been associated with 1 st Gen DES, especially after dual anti-platelet therapy termination. ${ }^{43,44}$ Over time, great effort has been made to improve the technology, thus reducing strut thickness from $140 \mu \mathrm{m}$ to approximately $70-80 \mu \mathrm{m}$, resulting in a dramatic reduction of thrombogenicity in bench studies. ${ }^{17,45}$ Advances in polymer technology have been enormous; new biocompatible polymers (PBMA or PVDF-HFP) result in less inflammation after stent implantation, with the consequence of more complete and functional endothelization. ${ }^{46,47}$ Also, CoCr-EES show fewer coating defects after implantation when compared to different DES, and this result was maintained over time and may improve vascular biocompatibility. ${ }^{25}$

Clinical data confirmed the outstanding performance of CoCr-EES, with lower rates of definitive/probable ST, TLR, and MACE. The PG for TLF was overperformed with CoCr-EES when compared with a competitor DES in small vessel disease. MACE and TLF rates were similar among diabetics and nondiabetics. ${ }^{27}$

At pathology, CoCr-EES revealed less inflammation and greater strut coverage when compared to 1 st Gen DES, while maintaining similar efficacy in reducing neointimal growth. Specifically, in small vessel disease, CoCr-EES have been shown to be less thrombogenic compared to 1st Gen DES; however, inflammation and restenosis remain a problem in this setting, and further technological and procedural progress is needed to improve patient outcomes.

\section{Conclusion}

In the DES era, small vessel CAD remains a great challenge for interventional cardiologists. Stent design and the material combination may provide better outcomes, especially in small vessel disease. CoCr-EES with thinner struts, biocompatible polymers, reduced drug load, and better radiopacity and trackability have shown excellent results from preclinical, clinical, and pathological studies in small vessel CAD.

\section{Acknowledgment}

CVPath Institute, Inc. received an educational grant from Abbott Vascular.

\section{Disclosure}

$\mathrm{RV}$ and MJ declare speakers fees from Abbott Vascular. ODS, $\mathrm{KY}$, and TK report no conflicts of interest in this work.

\section{References}

1. Kastrati A, Mehilli J, Pache J, et al. Analysis of 14 trials comparing sirolimus-eluting stents with bare-metal stents. $N$ Engl J Med. 2007;356(10):1030-1039.

2. Morice MC, Serruys PW, Sousa JE, et al; RAVEL Study Group. Randomized Study with the Sirolimus-Coated Bx Velocity BalloonExpandable Stent in the Treatment of Patients with de Novo Native Coronary Artery Lesions. A randomized comparison of a sirolimuseluting stent with a standard stent for coronary revascularization. N Engl J Med. 2002;346(23):1773-1780.

3. Moses JW, Leon MB, Popma JJ, et al; SIRIUS Investigators. Sirolimus-eluting stents versus standard stents in patients with stenosis in a native coronary artery. $N$ Engl J Med. 2003;349(14):1315-1323.

4. Eisenstein EL, Anstrom KJ, Kong DF. Clopidogrel use and longterm clinical outcomes after drug-eluting stent implantation. JAMA 2007;297(2):159-168.

5. Morice MC. Stenting for small coronary vessels. J Invasive Cardiol. 2003;15(7):377-379.

6. Elezi S, Dibra A, Mehilli J, et al. Vessel size and outcome after coronary drug-eluting stent placement: results from a large cohort of patients treated with sirolimus- or paclitaxel-eluting stents. J Am Coll Cardiol. 2006;48(7):1304-1309.

7. Hermiller JB, Fergus T, Pierson W, et al. Clinical and angiographic comparison of everolimus-eluting and paclitaxel-eluting stents in small coronary arteries: a post hoc analysis of the SPIRIT III randomized trial. Am Heart J. 2009;158(6):1005-1010.

8. Moore PA, Rosen CA, Carter KC. Assignment of the human FKBP12-rapamycin-associated protein (FRAP) gene to chromosome 1p36 by fluorescence in situ hybridization. Genomics. 1996;33(2):331-332.

9. Brown EJ, Albers MW, Shin TB, et al. A mammalian protein targeted by G1-arresting rapamycin-receptor complex. Nature. 1994;369(6483): 756-758.

10. Whitbeck MG, Applegate RJ. Second Generation Drug-Eluting Stents: A Review of the Everolimus-Eluting Platform. Clin Med Insights Cardiol. 2013;7:115-126.

11. Iqbal J, Gunn J, Serruys PW. Coronary stents: historical development, current status and future directions. Br Med Bull. 2013;106:193-211.

12. Menown IB, Noad R, Garcia EJ, Meredith I. The platinum chromium element stent platform: from alloy, to design, to clinical practice. $A d v$ Ther. 2010;27(3):129-141.

13. Kastrati A, Dibra A, Mehilli J, et al. Predictive factors of restenosis after coronary implantation of sirolimus- or paclitaxel-eluting stents. Circulation. 2006;113(19):2293-2300.

14. Tanimoto S, Daemen J, Tsuchida K, et al. Two-year clinical outcome after coronary stenting of small vessels using $2.25-\mathrm{mm}$ sirolimus- and paclitaxel-eluting stents: insight into the RESEARCH and T-SEARCH registries. Catheter Cardiovasc Interv. 2007;69(1):94-103. 
15. Kastrati A, Mehilli J, Dirschinger J, et al. Intracoronary stenting and angiographic results: strut thickness effect on restenosis outcome (ISAR-STEREO) trial. Circulation. 2001;103(23):2816-2821.

16. Lee Y, Tanaka A, Mori N, et al. Thin-strut drug-eluting stents are more favorable for severe calcified lesions after rotational atherectomy than thick-strut drug-eluting stents. J Invasive Cardiol. 2014;26(2):41-45.

17. Kolandaivelu K, Swaminathan R, Gibson WJ, et al. Stent thrombogenicity early in high-risk interventional settings is driven by stent design and deployment and protected by polymer-drug coatings. Circulation. 2011;123(13):1400-1409.

18. Finn AV, Joner M, Nakazawa G, et al. Pathological correlates of late drug-eluting stent thrombosis: strut coverage as a marker of endothelialization. Circulation. 2007;115(18):2435-2441.

19. Virmani R, Guagliumi G, Farb A, et al. Localized hypersensitivity and late coronary thrombosis secondary to a sirolimus-eluting stent: should we be cautious? Circulation. 2004;109(6):701-705.

20. Joner M, Finn AV, Farb A, et al. Pathology of drug-eluting stents in humans: delayed healing and late thrombotic risk. J Am Coll Cardiol. 2006;48(1):193-202.

21. Serruys PW, Farooq V, Kalesan B, et al. Improved safety and reduction in stent thrombosis associated with biodegradable polymer-based biolimus-eluting stents versus durable polymer-based sirolimus-eluting stents in patients with coronary artery disease: final 5-year report of the LEADERS (Limus Eluted From A Durable Versus ERodable Stent Coating) randomized, noninferiority trial. JACC Cardiovasc Interv. 2013;6(8):777-789.

22. Richardt G, Leschke M, Abdel-Wahab M, et al; RESOLUTE All Comers; RESOLUTE International Investigators. Clinical outcomes of the Resolute zotarolimus-eluting stent in patients with in-stent restenosis: 2-year results from a pooled analysis. JACC Cardiovasc Interv. 2013;6(9):905-913.

23. Chin-Quee SL, Hsu SH, Nguyen-Ehrenreich KL, et al. Endothelial cell recovery, acute thrombogenicity, and monocyte adhesion and activation on fluorinated copolymer and phosphorylcholine polymer stent coatings. Biomaterials. 2010;31(4):648-657.

24. Yazdani SK, Alexander S, Kolodgie FD, Virmani R. Stent coating integrity of first and second generation DES. EuroIntervention. 2012;8.

25. Joner M, Nakazawa G, Finn AV, et al. Endothelial cell recovery between comparator polymer-based drug-eluting stents. J Am Coll Cardiol. 2008;52(5):333-342.

26. Mehilli J, Dibra A, Kastrati A, Pache J, Dirschinger J, Schömig A; Intracoronary Drug-Eluting Stenting to Abrogate Restenosis in Small Arteries (ISAR-SMART 3) Study Investigators. Randomized trial of paclitaxel- and sirolimus-eluting stents in small coronary vessels. Eur Heart J. 2006;27(3):260-266.

27. Cannon LA, Simon DI, Kereiakes D, et al. The XIENCE nano everolimus eluting coronary stent system for the treatment of small coronary arteries: the SPIRIT Small Vessel trial. Catheter Cardiovasc Interv. 2012;80(4):546-553.

28. Stone GW, Ellis SG, Cannon L, et al; TAXUS V Investigators. Comparison of a polymer-based paclitaxel-eluting stent with a bare metal stent in patients with complex coronary artery disease: a randomized controlled trial. JAMA. 2005;294(10):1215-1223.

29. Turco MA, Ormiston JA, Popma JJ, et al. Reduced risk of restenosis in small vessels and reduced risk of myocardial infarction in long lesions with the new thin-strut TAXUS Liberté stent: 1-year results from the TAXUS ATLAS program. JACC Cardiovasc Interv. 2008;1(6): 699-709.

30. Schunkert H, Harrell L, Palacios IF. Implications of small reference vessel diameter in patients undergoing percutaneous coronary revascularization. J Am Coll Cardiol. 1999;34(1):40-48.

31. Elezi S, Kastrati A, Neumann FJ, Hadamitzky M, Dirschinger J, Schömig A. Vessel size and long-term outcome after coronary stent placement. Circulation. 1998;98(18):1875-1880.
32. Hermiller JB, Rutledge DR, Mao VW, et al. Clinical outcomes in real-world patients with small vessel disease treated with XIENCE ${ }^{\circledR}$ everolimus-eluting stents: one year results from the XIENCE ${ }^{\circledR}$ USA condition of approval post-market study. Catheter Cardiovasc Interv. 2014;84(1):7-16.

33. Ito H, Hermiller JB, Yaqub M, et al. Performance of everolimus-eluting versus paclitaxel-eluting coronary stents in small vessels: results from the SPIRIT III and SPIRIT IV clinical trials. J Interv Cardiol. 2011;24(6):505-513.

34. Stone GW, Midei M, Newman W, et al; SPIRIT III Investigators. Comparison of an everolimus-eluting stent and a paclitaxel-eluting stent in patients with coronary artery disease: a randomized trial. JAMA. 2008;299(16):1903-1913.

35. Bezenek S, Hermiller J, Lansky A, et al. Low stent thrombosis risk with the XIENCE $\mathrm{V}^{\circledR}$ Everolimus-Eluting Coronary Stent: evidence from randomized and single-arm clinical trials. J Interv Cardiol. 2011;24(4):326-341.

36. Hoffmann R, Mintz GS. Coronary in-stent restenosis - predictors, treatment and prevention. Eur Heart J. 2000;21(21):1739-1749.

37. Claessen BE, Smits PC, Kereiakes DJ, et al. Impact of lesion length and vessel size on clinical outcomes after percutaneous coronary intervention with everolimus- versus paclitaxel-eluting stents pooled analysis from the SPIRIT (Clinical Evaluation of the XIENCE V Everolimus Eluting Coronary Stent System) and COMPARE (Secondgeneration everolimus-eluting and paclitaxel-eluting stents in real-life practice) Randomized Trials. JACC Cardiovasc Interv. 2011;4(11): 1209-1215

38. Stone GW, Rizvi A, Newman W, et al; SPIRIT IV Investigators. Everolimus-eluting versus paclitaxel-eluting stents in coronary artery disease. N Engl J Med. 2010;362(18):1663-1674.

39. Serruys PW, Ruygrok P, Neuzner J, et al. A randomised comparison of an everolimus-eluting coronary stent with a paclitaxel-eluting coronary stent: the SPIRIT II trial. EuroIntervention. 2006;2(3):286-294.

40. Otsuka F, Vorpahl M, Nakano M, et al. Pathology of second-generation everolimus-eluting stents versus first-generation sirolimus- and paclitaxel-eluting stents in humans. Circulation. 2014;129(2): 211-223.

41. Nakazawa G, Finn AV, Joner M, et al. Delayed arterial healing and increased late stent thrombosis at culprit sites after drug-eluting stent placement for acute myocardial infarction patients: an autopsy study. Circulation. 2008;118(11):1138-1145.

42. Bavry AA, Kumbhani DJ, Helton TJ, Borek PP, Mood GR, Bhatt DL. Late thrombosis of drug-eluting stents: a meta-analysis of randomized clinical trials. Am J Med. 2006;119(12):1056-1061.

43. Nordmann AJ, Briel M, Bucher HC. Mortality in randomized controlled trials comparing drug-eluting vs. bare metal stents in coronary artery disease: a meta-analysis. Eur Heart J. 2006;27(23):2784-2814.

44. Ong AT, McFadden EP, Regar E, de Jaegere PP, van Domburg RT, Serruys PW. Late angiographic stent thrombosis (LAST) events with drug-eluting stents. J Am Coll Cardiol. 2005;45(12):2088-2092.

45. Horita Y, Namura M, Ikeda M, et al. 'Which Des Is the Most Appropriate for Very Small Target Vessels? Experimental Study of Stent Expandable Performance with Ses, Pes, Zes and Ees'. Cardiovasc Interv Ther. 26, 2011:24-30.

46. Stefanini GG, Byrne RA, Serruys PW, et al. Biodegradable polymer drug-eluting stents reduce the risk of stent thrombosis at 4 years in patients undergoing percutaneous coronary intervention: a pooled analysis of individual patient data from the ISARTEST 3, ISAR-TEST 4, and LEADERS randomized trials. Eur Heart J. 2012;33(10):1214-1222.

47. Bangalore S, Toklu B, Amoroso N, et al. Bare metal stents, durable polymer drug eluting stents, and biodegradable polymer drug eluting stents for coronary artery disease: mixed treatment comparison meta-analysis. BMJ. 2013;347:f6625. 
Medical Devices: Evidence and Research

Dovepress

\section{Publish your work in this journal}

Medical Devices: Evidence and Research is an international, peerreviewed, open access journal that focuses on the evidence, technology, research, and expert opinion supporting the use and application of medical devices in the diagnosis, treatment and management of clinical conditions and physiological processes. The identification of novel devices and optimal use of existing devices which will lead to improved clinical outcomes and more effective patient management and safety is a key feature. The manuscript management system is completely online and includes a quick and fair peer-review system. Visit http://www. dovepress.com/testimonials.php to read real quotes from authors.

Submit your manuscript here: http://www.dovepress.com/medical-devices-evidence-and-research-journal 